\title{
Produção e biometria do milho verde irrigado com água salina sob frações de lixiviação ${ }^{1}$
}

\author{
José F. de Carvalho', Celestino J. Tsimpho², Ênio F. de F. e Silva², \\ Pedro R. F. de Medeiros ${ }^{2}$, Max H. Vieira dos Santos ${ }^{2} \&$ Alexandre N. dos Santos ${ }^{2}$
}

RESU M O

0 trabalho teve como objetivo avaliar o desempenho da cultura do milho em relação a produção e biometria, irrigado por gotejamento com água salina e sob diferentes frações de lixiviação em estação lisímetrica de drenagem. O s tratamentos consistiram de dois níveis de salinidade da água (CEa- 1,2 e 3,3 dS $\mathrm{m}^{-1}$ ) e cinco frações de lixiviação (FL- 0, 5, 10, 15 e 20\%) em delineamento inteiramente casualizado em esquema fatorial $2 \times 5$. 0 experimento foi conduzido na área experimental do Departamento de Tecnologia Rural da Universidade Federal Rural de Pernambuco, Recife, PE. Foram avaliados a produtividade de polpa hidratada e desidratada e de espiga com e sem palha, matéria fresca e seca da parte aérea, diâmetro de caule e altura de planta. As variáveis produção de grãos verdes, matéria seca e fresca da parte aérea apresentaram resultados semelhantes, obtendo elevados valores quando se utilizou água de $3,3 \mathrm{dS} \mathrm{m}^{-1} \mathrm{com}$ a fração de lixiviação de $10 \%$, obtendo efeito deletério com o aumento da fração de lixiviação.

Palavras chaves: Zea mays L., irrigação, salinidade, estresse salino

\section{Production and biometry of green corn irrigated with saline water under leaching fractions}

\section{A B STRACT}

The objective of present study was to evaluate the corn crop in respect to the production and biometry under drip irrigation system with saline waters at lysimeter station of drainage. The treatments consisted of two levels of water sal inity (CEa - 1.2 and $3.3 \mathrm{dS} \mathrm{m}^{-1}$ ) and five leaching fractions (LF - 0, 5, 10, 15 and $20 \%)$, in a completely randomized experimental design $(2 \times 5$ factorial $)$. The experiment was conducted at the Department of Rural Technology of the UFRPE, Recife/PE. The productivity of hydrated and dried pulp and of weight of cob with and without husks, fresh and dry matter of the aerial parts, stem diameter and height of plant were evaluated. The productivity of hydrated pulp and the fresh and dry matter of the aerial parts presented high values when water of $3.3 \mathrm{dS} \mathrm{m}^{-1}$ was used with leaching fraction of $10 \%$, obtaining decreasing effect with the increase of the leaching fraction.

Key words: Zea mays L., irrigation, salinity, saline stress

\footnotetext{
${ }^{1}$ Trabalho apresentado durante a II Reunião Sulamericana para Manejo e Sustentabilidade da Irrigação em Regiões Áridas e Semiáridas, Cruz das Almas, BA - 03 a 07 de abril de 2011

2 Departamento de Tecnologia Rural/U FRPE. R. Dom Manoel de Medeiros, s/n, Dois Irmãos, CEP 52171-900, Recife, PE. Fone: (81) $3320-6279$. E-mail: carvalho.jcarvalho20@gmail.com; ctsimpho@yahoo.com.br; enio.silva@pq.cnpq.br; prfmede@yahoo.com.br;maxhvs@gmail.com; alexandrens14@yahoo.com.br
} 


\section{INTRODUÇÃO}

A irrigação é uma das tecnologias aplicadas na agricultura que mais tem contribuído para o aumento na produção de alimentos. No entanto, a qualidade da água apresenta restrições à agricultura irrigada e pode resultar em obstáculo ao desenvolvimento das culturas, além de acelerar a degradação do solo (Silva et al., 2005).

O Nordeste brasileiro apresenta uma área potencial de irrigação estimada em 6 milhões de hectares e, atualmente, $25 \%$ dos perímetros irrigados existentes na região Nordeste estão salinizados (Leite, 2005), principalmente por causa da ausência de práticas de manejo adequado da água de irrigação.

Em regiões áridas e semiáridas, a salinização decorre da natureza física e química dos solos, do regime pluvial e da alta evaporação. Naturalmente, o uso de irrigação acarreta a incorporação de sais ao perfil do solo, por conter na água sais solúveis; devido ao seu uso continuado em irrigações, na ausência de lixiviação, o sal se deposita na zona do sistema radicular e na superfície do solo, decorrente da evaporação da água. Segundo Holanda Filho et al. (2011), o uso de água salina aumenta os teores de magnésio e sódio no solo, a porcentagem de sódio trocável, a razão de adsorção de sódio, modificando suas característica.

A salinização do solo progride quando a quantidade de sais, nele acumulada pela água de irrigação, é maior que a quantidade removida pela água de drenagem (Armas et al., 2010; Freire \& Freire, 2007). Os sais em excesso prejudicam o crescimento das plantas, em virtude dos efeitos diretos sobre o potencial osmótico e dos íons potencialmente tóxicos presentes em elevadas concentrações na solução do solo (Silva et al., 2008).

O milho é uma cultura moderadamente tolerante à salinidade, apresentando redução na sua produção quando a condutividade elétrica do extrato de saturação do solo é superior a 2,7 dS m ${ }^{-1}$ (Mcwilliams, 2003).

A redução dos componentes de rendimento da cultura do milho em função do aumento da salinidade do solo é relatada por diversos autores. Willadinno et al. (1994) verificaram que a produção de grãos, de oito genótipos de milho cultivados em área salina, decresceu de 24 a 60\% em relação a área não salina. Katerji et al. (2001; 2004) também constataram que a produtividade do milho foi reduzida em função do aumento da salinidade do solo.

Segundo Garcia et al. (2007), o aumento da salinidade do solo decorrente da irrigação com água salina, provocou na variedade de milho UFVM 100, redução da fotossíntese, condutância estomática, transpiração e da eficiência do uso de água na produtividade; matéria seca da parte aérea e das raízes; taxas de crescimento absoluto e relativo, de assimilação líquida, área foliar total das plantas; peso de grãos, peso médio das espigas sem palha.
Porém, a disponibilidade de água de boa qualidade para irrigação esta cada vez mais difícil. Com isso a utilização de práticas de manejo adequado da água salina torna-se uma alternativa viável quando se trabalha com espécies tolerantes. Uma prática de manejo bastante utilizada em áreas que utilizam água de qualidade inferior é a fração de lixiviação ("Leaching Fraction") que é uma quantidade extra de água, relativa à aquela que é aplicada e penetra no solo, acarretando lixiviação dos sais. Como definido pelo U.S. Salinity Laboratory (Richards, 1954), é a fração de água de irrigação que deve passar para abaixo da zona radicular, visando manter a salinidade em um nível específico.

A necessidade (requerimento) de lixiviação (NL) é a fração mínima da quantidade total de água aplicada que deve passar através da zona radicular, para prevenir a redução no rendimento da cultura. Para Rhoades et al. (1992), a necessidade de lixiviação é um aspecto do manejo da irrigação, que influencia a resposta das culturas à salinidade da água de irrigação.

Objetivou-se nesse trabalho avaliar a cultura do milho (Hibrido AG1051) em relação aos parâmetros biométricos e de produção quando irrigado com águas salina combinadas com diferentes frações de lixiviação em Neossolo Quartzarênico.

\section{Material e MÉTOdos}

O experimento foi conduzido na Estação Lisimétrica do Departamento de Tecnologia Rural (DTR), na Universidade Federal Rural de Pernambuco (UFRPE), em Recife, PE, com coordenadas geográficas de $8^{\circ} 01^{\prime}$ ' 05" de latitude Sul, 34 $56^{\circ}$ $48^{\prime \prime}$ de longitude Oeste e altitude de 6,5 m. De acordo com a classificação de Koeppen, o clima da região é do tipo As, megatérmico tropical (tropical úmido), com precipitação pluviométrica média anual (outono e inverno) de $1501 \mathrm{~mm} \mathrm{e}$ temperatura média de $26^{\circ} \mathrm{C}$.

O solo foi classificado como Neossolo Quartzarênico (Albuquerque Filho et al., 2009) de textura arenosa, as características físico-hídricas encontram-se na Tabela 1, para a camada 0 a $20 \mathrm{~cm}$. Foram realizadas adubação de fundação para nitrogênio $(\mathrm{N})$, potássio $(\mathrm{K})$ e fósforo $(\mathrm{P})$, segundo recomendação de Cavalcanti (2008), e de cobertura com nitrogênio (N) parcelada em duas partes iguais aos 20 e 40 dias após a emergência (DAE).

A área total ocupada pelos lisímetros é 464,40 m² (18,0 m de largura por 25,80 m de comprimento), com 40 lisímetros de drenagem provido de dreno de fundo ligado a um dispositivo para a coleta do efluente. Conjugado a cada sistema de drenagem existe um piezômetro individual com escala milimétrica, para medir a variação de nível da água dentro dos

Tabela 1. Características físico-hídricas dos solos lisímetros

\begin{tabular}{|c|c|c|c|c|c|c|c|c|c|c|c|}
\hline \multicolumn{2}{|c|}{ Densidade $-\mathrm{kg} \mathrm{dm}^{-3}$} & \multirow{2}{*}{$\begin{array}{l}\text { Pt } \\
\%\end{array}$} & \multicolumn{3}{|c|}{ Granolumetria - \% } & \multirow{2}{*}{ Ad } & \multirow{2}{*}{ GF } & \multicolumn{2}{|c|}{ Umidade $\left(\mathrm{g} \mathrm{g}^{-1}\right)$} & \multirow{2}{*}{ AD } & \multirow{2}{*}{$\begin{array}{c}\text { Ko } \\
\mathrm{cm} \mathrm{h}^{-1}\end{array}$} \\
\hline dg & $d p$ & & $\mathrm{Ar}$ & A & $\mathbf{S}$ & & & $0,1 \mathrm{~atm}$ & $15 \mathrm{~atm}$ & & \\
\hline 1,65 & 2,57 & 35,67 & 91,07 & 3,60 & 5,33 & 3,6 & 0,0 & 6,39 & 2,01 & 4,3 & 13,17 \\
\hline
\end{tabular}

dg - densidade global; dp - densidade das partículas; Pt - porosidade total; Ar - areia; A - argila; S - silte; Ad - argila dispersa em água; GF - grau de floculação; AD - água disponível; Ko - condutividade hidráulica saturada 
respectivos lisímetros. A profundidade do perfil do solo dentro de cada lisimetro é de $0,75 \mathrm{~m}$, ficando uma borda de $0,10 \mathrm{~m}$ acima da superfície do solo.

Utilizou o híbrido de milho (Zea mays L.) AG 1051, classificado como especial destina-se exclusivamente ao consumo humano. É utilizado principalmente como milho verde, tanto in natura, como para processamento em conserva. A semeadura ocorreu em 09/11/2010 e a colheita em 21/01/2011 (72 dias após a semeadura). O tratamento fitossanitário preventivo para o controle da lagarta do cartucho (Spodoptera frugiperda) foi realizado aos dez dias após a emergência.

Utilizou-se irrigação por gotejamento, com espaçamentos de 0,5 m entre emissores autocompensantes na linha e de $1,2 \mathrm{~m}$ entre linhas; com vazão média de $4,06 \mathrm{~L} \mathrm{~h}^{-1}$, a uma pressão de serviço de 13,5 mca, aferido em teste de uniformidade.

O manejo da irrigação foi realizado diariamente, as lâminas de irrigação foram estimadas com base na ETc, de acordo com a Equação 1.

$$
\mathrm{ET}_{\mathrm{c}}=\mathrm{ET}_{\mathrm{o}} \times \mathrm{K}_{\mathrm{c}} \times \mathrm{Kl}_{\text {med }}
$$

em que:

ET - evapotranspiração da cultura, $m m$ dia $^{-1}$

$\mathrm{ET}_{\mathrm{o}}^{\mathrm{c}}$ - evapotranspiração de referência de Penman-Monteith, $\mathrm{mm} \mathrm{dia}^{-1}$

$\mathrm{K}$ - coeficiente de cultivo, adimensional

$\mathrm{Kl}_{\text {med }}$ - coeficiente de localização médio, adimensional

Para determinação do $\mathrm{K}_{\text {méd }}$, utilizou-se a média de quatro valores de coeficiente de localização $(\mathrm{Kl})$, segundo diversos autores, citados por Pizarro (1996), que dependem do valor da fração de área sombreada pelo cultivo. Os valores de Kl variaram em função da área sombreada pelo cultivo de acordo com o desenvolvimento das plantas.

Os dados utilizados para determinação da ETo pelo método de Penman-Monteith e a precipitação pluviométrica utilizadas na estimativa das lâminas de irrigação, em função dos tratamentos utilizados, foram obtidas em estação meteorológica automatizada instalada junto da área experimental. Os valores de $\mathrm{K}_{\mathrm{c}}$ utilizados diariamente de acordo com a fase fenológica da cultura, foram, 0,70 (da emergência até 10\% do desenvolvimento); 1,15 (10\% do desenvolvimento até $75 \%$ do desenvolvimento) e 1,20 (floração até a colheita), de acordo com FAO (2006).
A água salina utilizada nas irrigações foi preparada em dois tanques com capacidade de $500 \mathrm{~L}$ cada, mediante a adição de $\mathrm{NaCl}$ e $\mathrm{CaCl}_{2}$, na proporção de 1:2, Ca:Na com base molar, em quantidades necessárias para obtenção de duas condutividades elétricas de água de irrigação (CEa) de 1,20 e $3,3 \mathrm{dS} \mathrm{m}^{-1}$.

Foi adotado o delineamento inteiramente casualizado em esquema fatorial $2 \times 5$ com quatro repetições, totalizando 40 parcelas experimentais.Os tratamentos constituíram-se de dois níveis de condutividade elétrica da água de irrigação (1,2 e 3,3 $\left.\mathrm{dS} \mathrm{m}^{-1}\right)$ e cinco frações de lixiviação $(0,5,10,15$ e $20 \%)$.

As variáveis analisadas de produção foram produtividade da polpa hidratada ( $\mathrm{PPH})$, produtividade da polpa desidratada(PPD), massa de espiga com palha (ECP) e massa de espiga sem palha (ESP). O crescimento das plantas foi avaliado, mediante a determinação do diâmetro do caule (D), altura de inserção de espigas (AIE), altura das plantas (A), massa da matéria fresca da parte aérea (MFPA) e massa da matéria seca da parte aérea (MSPA). Na obtenção dos matérias vegetais (polpa desidratada e parte aérea) secas, as amostras foram acondicionadas em sacos de papel e após secagem em estufa de circulação forçada de ar à temperatura de $65{ }^{\circ} \mathrm{C}$, até atingir massa constante, em balança analítica de precisão $0,01 \mathrm{~g}$.

Os dados obtidos foram submetidos à análise de variância pelo teste $\mathrm{F}$ a 5\% de significância com o auxilio do programa SAS. Os dois níveis de salinidade da água foram comparados pelo teste de Tukey (5\%) e as frações de lixiviação foram submetidas à análise de regressão.

\section{RESULTADOS E DISCUSSÃO}

De acordo com a análise de variância, o fator salinidade da água afetou $(\mathrm{P}<0,05)$ as variáveis espiga sem palha e matéria seca da parte aérea. O fator fração de lixiviação afetou significativamente as variáveis espiga sem palha, produtividade de polpa hidratada, altura de inserção de espiga, matéria fresca e seca da parte aérea. Ocorrendo também efeitos significativos na interação entre os fatores para as variáveis espiga sem palha, produtividade de polpa hidratada e matéria seca da parte aérea (Tabela 2).

Tabela 2. Q uadro de AN O VA para as variáveis de produção e biometria do híbrido de milho AG 1051

\begin{tabular}{|c|c|c|c|c|c|c|}
\hline & F. V. & $\mathrm{CE}$ & $\mathrm{FL}$ & CE*FL & ERRO & CV(\%) \\
\hline $\begin{array}{l}\frac{0}{8} \\
\frac{8}{8} \\
\frac{8}{8} \\
\frac{0}{0} \\
\frac{0}{0}\end{array}$ & $\begin{array}{l}\text { G. L. } \\
\text { ECP } \\
\text { ESP } \\
\text { PPH } \\
\text { PPD } \\
\text { D } \\
\text { AIE } \\
\text { A } \\
\text { MFPA } \\
\text { MSPA }\end{array}$ & $\begin{array}{c}1 \\
525,63^{\text {ns }} \\
6786,03 \text { ** } \\
568,74^{\text {ns }} \\
18,77^{\text {ns }} \\
1,93^{\text {ns }} \\
288,85^{\text {ns }} \\
281,27^{\text {ns }} \\
39,70^{\text {ns }} \\
156,30 \text { ** }\end{array}$ & $\begin{array}{c}4 \\
938,31 \text { ns } \\
4873,59 * * \\
1797,72 * * \\
45,91^{\mathrm{ns}} \\
3,94^{\mathrm{ns}} \\
231,20^{*} \\
260,14^{\mathrm{ns}} \\
614,42 * * \\
133,80 * *\end{array}$ & $\begin{array}{c}4 \\
157,06^{\text {ns }} \\
2606,21^{* *} \\
764,26^{*} \\
2,546^{\text {ns }} \\
1,59^{\text {ns }} \\
176,60^{\text {ns }} \\
76,48^{\text {ns }} \\
214,69^{\text {ns }} \\
43,51^{*}\end{array}$ & \begin{tabular}{r}
\multicolumn{1}{c}{30} \\
609,84 \\
247,86 \\
239,01 \\
19,07 \\
1,76 \\
67,19 \\
194,56 \\
96,72 \\
12,36
\end{tabular} & $\begin{array}{r}7,49 \\
6,94 \\
8,45 \\
13,35 \\
6,08 \\
6,90 \\
6,68 \\
8,63 \\
10,33\end{array}$ \\
\hline
\end{tabular}

F. V. - fonte de variação, G.L. - graus de liberdade, CE - condutividade elétrica, FL - fração de lixiviação, CE* FL - interação entre os fatores de variação, CV - coeficiente de variação, ECP - massa de espiga com palhas, ESP - massa de espiga sem palhas, PPH - produtividade de polpa hidratada, PPD - produtividade de polpa desidratada, D - diâmetro do caule, AIE - altura de inserção de espigas, A - altura de plantas, MFPA - matéria fresca da parte aérea e MSPA - matéria seca da parte aérea, ns - não significativo, * e ** - significativo à 5 e $1 \%$ da probabilidade 
A salinidade da água de irrigação não afetou o desenvolvimento vegetativo da cultura (altura e diâmetro de caule), como também as variáveis ECP, PPH, PPD, MFPA (Tabelas 3 e 4), devido principalmente ao efeito antagônico a partir das maiores frações de lixiviação sobre o acúmulo de sais do solo. De acordo com Santos et al. (2005); Assis Júnior et al. (2007); Wilson et al. (2006), o excedente da água de irrigação lixivia o excesso de sais no perfil do solo, resultando em menor efeito da salinidade no ambiente radicular, o que favorece o crescimento e o desenvolvimento da cultura.

As variáveis massa da espiga sem palha (ESP) e matéria seca da parte aérea (MSPA) foram afetadas pela salinidade da água de irrigação (Figuras 1A e 1C); com a utilização de água com 1,2 $\mathrm{dS} \mathrm{m}^{-1}$ a variável ESP obteve tendência decrescente linear com o aumento da fração de lixiviação numa proporção de $9 \%$ entre as frações de lixiviação 0 e $20 \%$. Evidenciando que baixas concentrações de sais são facilmente carreados pela água, principalmente em solo de textura arenosa, sendo que o seu manejo deve ser imprescindível por que tal evento pode provocar em ultima instância deficiência nutricional. Resultados também encontrados por Gomes et al. (2011) e Blanco et al. (2008).

Com a utilização da água com $3,3 \mathrm{dS} \mathrm{m}^{-1}$, tais variáveis tiveram efeito semelhante, com valores baixos nas frações extremas de lixiviação e valores elevados para a fração de lixiviação de $10 \%$ (intermediária). Neste caso ocorreram dois efeitos simultâneos adversos, efeito de excesso de sais (toxidez) e efeito de lavagem dos sais do perfil do solo (deficiência).

O desenvolvimento normal das plantas exige a realização de uma série de processos físicos, químicos e biológicos que dependem fundamentalmente da disponibilidade de água. Sob salinidade, há redução das massas frescas em várias espécies vegetais, provavelmente devido à diminuição da absorção de água e fotossíntese. Segundo Rhoades et al. (1992), a diminuição do potencial osmótico associada a frações de lixiviação pequenas e ao uso de águas de irrigação salinas, torna-se especialmente perigoso, porque o nível de "estresse crítico" do potencial total será alcançado mais rapidamente, principalmente para as cultura sensível à salinidade.

Em relação às variáveis PPH, MFPA e AIE (Figuras 1B, 1D e $1 \mathrm{E})$, estas também sofreram os efeitos simultâneos adversos oriundos da combinação de diferentes frações de lixiviação com a utilização de água na irrigação com $3,3 \mathrm{dS} \mathrm{m} \mathrm{m}^{-1}$. Para a variável produtividade de polpa hidratada $(\mathrm{PPH})$, encontramos diferenças de $30 \%$ entre as frações 5 e $20 \%$ (Figura 1B). Para as variáveis MFPA e AIE, as frações de 5 e $10 \%$ tiveram praticamente o mesmo valor, divergindo em 20 e $10 \%$ respectivamente, dos valores obtidos na fração de lixiviação de $20 \%$.

Segundo Rhoades et al. (1992), a salinidade da água de irrigação e a fração de lixiviação são combinadas para se estabelecer o nível de distribuição de estresse osmótico na zona radicular e o valor do potencial osmótico médio. Segundo Oliveira et al. (2005), o aumento da fração de lixiviação proporcionou redução na salinidade média do solo. Em solos com boa drenagem (solos franco arenosos), a concentração de sais pode ser reduzida, por meio de lâminas de lavagens (Duarte et al., 2007).

A produtividade de polpa hidratada máxima obtida foi de 185,70 e 213,65 g planta $^{-1}$, a partir do espaçamento utilizado teve-se uma produção de 3,10 e $3,56 \mathrm{Mg} \mathrm{ha}^{-1}$ para as águas de 1,2 e $3,3 \mathrm{dS} \mathrm{m}^{-1}$ respectivamente, para a fração de lixiviação de $5 \%$ (Tabela 5).

Tabela 3. Média da condutividade elétrica do extrato de saturação do solo (CEes), em função dos níveis de salinidade da água de irrigação e das frações de lixiviação, durante o ciclo do híbrido de milho AG 1051

\begin{tabular}{|c|c|c|c|c|c|c|c|}
\hline \multirow{3}{*}{ Tratamentos } & \multirow{3}{*}{$\begin{array}{l}\mathbf{F L} \\
\%\end{array}$} & \multicolumn{3}{|c|}{$0-0,20 \mathrm{~m}$} & \multicolumn{3}{|c|}{$0,20-0,40 m$} \\
\hline & & AS & 20 DAS & 70 DAS & AS & 20 DAS & 70 DAS \\
\hline & & \multicolumn{6}{|c|}{$d S m^{-1}$} \\
\hline \multirow{5}{*}{ CE 1,2} & 0 & 0,70 & 0,78 & 1,43 & 0,65 & 0,51 & 0,98 \\
\hline & 5 & 0,60 & 0,65 & 1,16 & 0,87 & 0,73 & 0,99 \\
\hline & 10 & 0,61 & 0,66 & 0,96 & 0,58 & 0,66 & 0,78 \\
\hline & 15 & 0,77 & 0,40 & 0,95 & 0,70 & 0,41 & 1,02 \\
\hline & 20 & 0,49 & 0,53 & 0,93 & 0,65 & 0,63 & 1,19 \\
\hline \multirow{5}{*}{ CE 3,3} & 0 & 0,56 & 1,26 & 2,06 & 0,53 & 0,57 & 1,40 \\
\hline & 5 & 0,77 & 0,86 & 1,59 & 0,71 & 1,15 & 1,40 \\
\hline & 10 & 0,47 & 0,84 & 1,43 & 1,00 & 0,92 & 1,08 \\
\hline & 15 & 0,55 & 0,61 & 1,96 & 0,95 & 0,68 & 1,42 \\
\hline & 20 & 0,48 & 0,59 & 1,63 & 0,83 & 0,67 & 1,66 \\
\hline
\end{tabular}

* AS - antes da semeadura, DAS - dias após semeadura, CE - condutividades elétricas de 1,2 e 3,3 dS m ${ }^{-1}$, FL - fração de lixiviação

Tabela 4. Efeito da condutividade elétrica do solo em função das variáveis respostas

\begin{tabular}{|c|c|c|c|c|c|c|c|c|c|}
\hline \multirow{2}{*}{ Trat. } & ECP & ESP & PPH & PPD & D & AIE & $A$ & MFPA & MSPA \\
\hline & \multicolumn{4}{|c|}{ (g planta $\left.{ }^{-1}\right)$} & \multicolumn{3}{|c|}{$(\mathrm{cm})$} & \multicolumn{2}{|c|}{ (g planta $\left.{ }^{-1}\right)$} \\
\hline CE 1,2 & $333,5 a$ & $240,0 a$ & 179,1 a & $32,0 \mathrm{a}$ & $2,16 a$ & $116,2 \mathrm{~b}$ & 206,3 a & 113,0 a & 32,06 b \\
\hline
\end{tabular}

Trat - tratamentos; médias seguidas de mesma letra na mesma coluna não diferem estatisticamente. CE 1,2 - condutividade elétrica de 1,2 dS $\mathrm{m}^{-1}$, CE 3,3 - condutividade elétrica de 3,3 dS $\mathrm{m}^{-1}$, ECP - massa de espiga com palhas, ESP - massa de espiga sem palhas, PPH - produtividade de polpa hidratada, PPD - produtividade de polpa desidratada, D - diâmetro do caule, AIE - altura de inserção de espigas, A - altura de plantas, MFPA - matéria fresca da parte aérea e MSPA - matéria seca da parte aérea 
A.
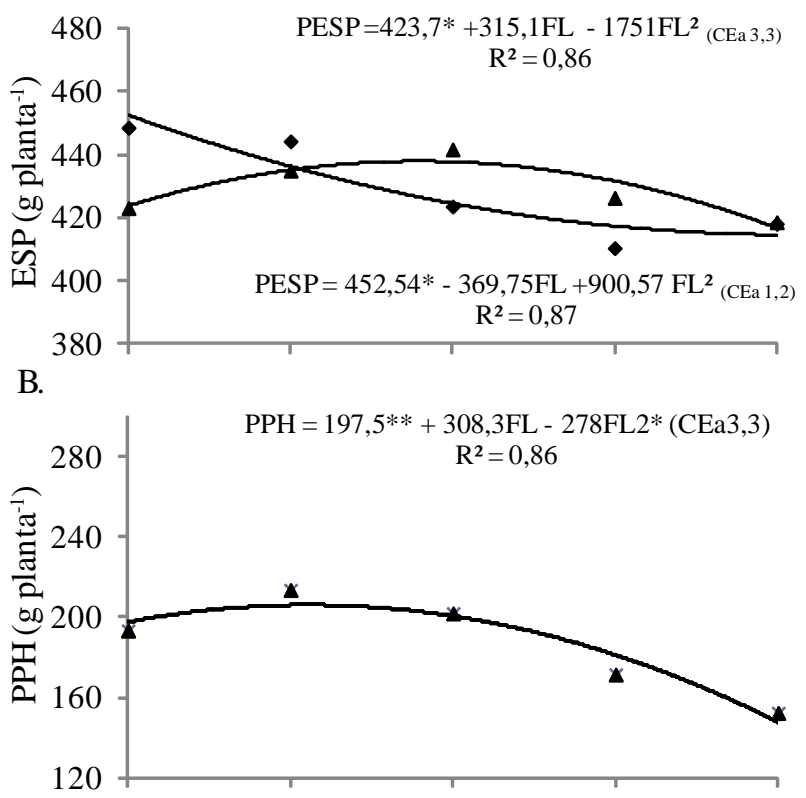

C.

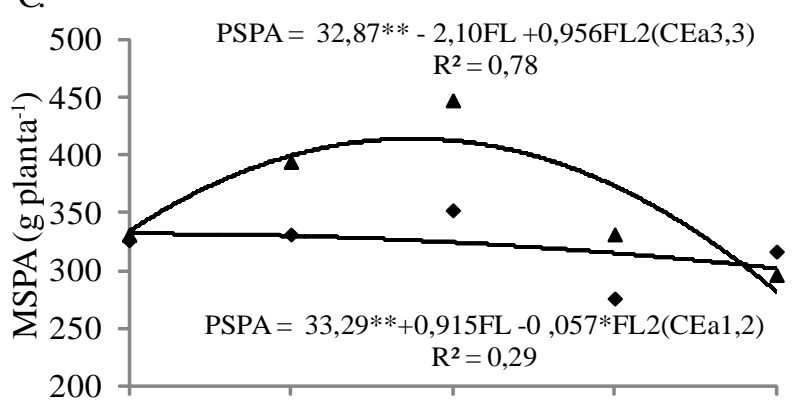

D.

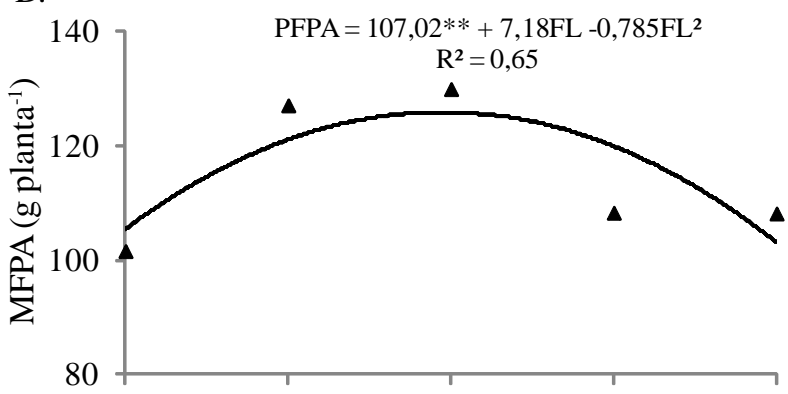

E.

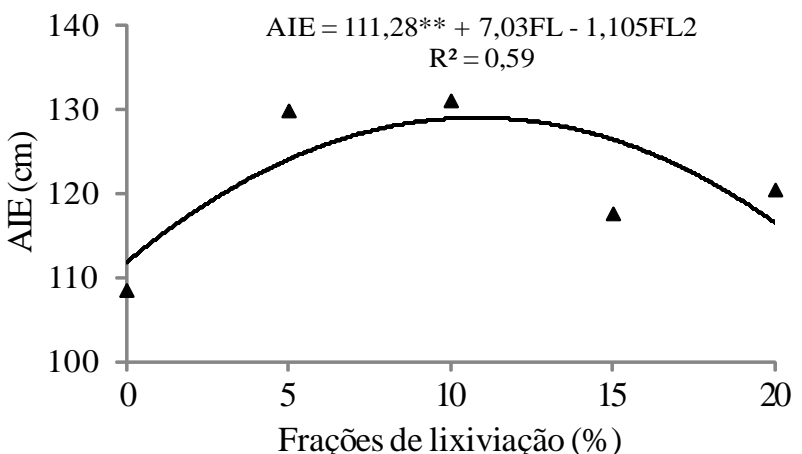

Figura 1. Análises de regressão e equações de ajustes para as variáveis espiga sem pal ha - ESP $(A)$, produtividade de polpa hidratada - PPH (B), massa seca da parte aérea MSPA (C), massa fresca da parte aérea - M FPA (D) e al tura de inserção da espiga - AIE (E), em função das frações de lixiviação e dos níveis de salinidade do solo
Tabela 5. Valores médios representando a interação entre os fatores frações de lixiviação e níveis de salinidade do solo

\begin{tabular}{|c|c|c|c|c|c|c|}
\hline \multirow{3}{*}{$\begin{array}{c}\text { Fração de } \\
\text { lixiviação } \\
\text { (\%) }\end{array}$} & \multicolumn{2}{|c|}{ ESP } & \multicolumn{2}{|c|}{ PPH } & \multicolumn{2}{|c|}{ MSPA } \\
\hline & \multicolumn{6}{|c|}{ CE (dS $\left.m^{-1}\right)$} \\
\hline & 1,2 & 3,3 & 1,2 & 3,3 & 1,2 & 3,3 \\
\hline 0 & $448,6 \mathrm{Aa}$ & $423,1 \mathrm{Aa}$ & $181,5 \mathrm{Aa}$ & $193,5 \mathrm{Aa}$ & $32,6 \mathrm{Aa}$ & $33,1 \mathrm{Ab}$ \\
\hline 5 & $444,3 \mathrm{Aa}$ & $435,0 \mathrm{Aa}$ & $185,7 \mathrm{Aa}$ & $213,6 \mathrm{Aa}$ & 33,1 Aa & $39,4 \mathrm{Ab}$ \\
\hline 10 & $423,6 \mathrm{Aa}$ & $441.8 \mathrm{Aa}$ & $182.9 \mathrm{Aa}$ & $202,0 \mathrm{Aa}$ & $35,2 \mathrm{Ba}$ & $44,7 \mathrm{Aa}$ \\
\hline 15 & $410,5 \mathrm{Ab}$ & $426,4 \mathrm{Aa}$ & $170,1 \mathrm{Aa}$ & $171,6 \mathrm{Ab}$ & $27,6 \mathrm{Aa}$ & $33,1 \mathrm{Ab}$ \\
\hline 20 & $418,2 \mathrm{Aa}$ & $418,7 \mathrm{Aa}$ & $175,3 \mathrm{Aa}$ & $152,5 \mathrm{Ab}$ & $31,7 \mathrm{Aa}$ & $29,6 \mathrm{Ab}$ \\
\hline
\end{tabular}

* Médias seguidas da mesma letra maiúsculas nas linhas e minúsculas nas colunas não diferem entre si pelo teste de Tukey em nível de 0,05 de probabilidade

Segundo Bezerra et al. (2010), para o mesmo híbrido de milho, obtiveram produtividades de polpa de 5,21; 5,18; 5,09 e 5,35 $\mathrm{Mg} \mathrm{ha}^{-1}$ utilizando águas com condutividade elétrica de 0,8 ; 2,2; 3,6 e 5,0 dS m ${ }^{-1}$ respectivamente. Resultado também semelhante encontrado por Lacerda et al. (2011).

Para as variáveis matéria fresca e seca da parte aérea, as maiores produções foram de 129,93 e 44,76 $\mathrm{g} \mathrm{planta}^{-1}$ para a água com $3,3 \mathrm{dS} \mathrm{m}^{-1} \mathrm{e}$ a fração de lixiviação de $10 \%$. Diversas culturas apresentam elevados valores de material vegetal quando submetidas a ambientes extremamente salinos, devido basicamente pela elevada concentração de sais absorvidos. A necessidade de consumo de água para produzir uma unidade de matéria seca depende de cada espécie ou variedade vegetal, do estádio de desenvolvimento, da densidade da associação vegetal, das condições ambientais e, sobretudo da disponibilidade hídrica e evaporativa do ar (Garcia et al., 2007).

Analisando os resultados oriundos da interação entre os fatores (Tabela 5), observa-se que para as variáveis massa de espiga sem palha e produtividade de polpa hidratada, os níveis de salinidade da água tiveram pouca influência, porém quando submetidos a elevadas frações de lixiviação, estes provocaram efeito deletério significativo. Para a variável matéria seca da parte aérea, esta sofreu influência de ambos os fatores analisados, observando elevados valores para a água de maior salinidade interagindo com a fração de lixiviação de $10 \%$.

Em solos arenosos, a água aplicada na irrigação permanece mais disponível as plantas, aumentando assim o potencial osmótico na zona radicular, diminuindo de forma progressiva o efeito dos sais sobre as raízes. A partir de um manejo adequado, solos de textura arenosa podem ser explorados mesmo com a utilização de águas com elevada concentração salina (Baghalian et al., 2008).

\section{ConClusõEs}

1. A irrigação com água de $1,2 \mathrm{dS} \mathrm{m}^{-1}$ não teve efeito deletério sobre a cultura do milho, principalmente quando associada a utilização de frações de lixiviação;

2. A técnica da fração de lixiviação de uma forma geral teve efeito direto na cultura do milho em solo arenoso, principalmente quando se utilizou águas de elevada concentração de sais; 
3. Quanto à produção de grãos verdes, a adoção do manejo com frações de lixiviação deve ser imprescindível na irrigação com águas de elevada concentração salina, em que recomendase a fração de lixiviação de $10 \%$ quando se utiliza águas com salinidade em torno de $3,3 \mathrm{dS} \mathrm{m}^{-1}$.

\section{Agradecimentos}

Os autores agradecem à CAPES/PNPD, FACEPE e ao CNPq pelo fornecimento de bolsas de Mestrado, Doutorado e PósDoutoramento, e ao programa de Pós-Graduação em Engenharia Agrícola da Universidade Federal Rural de Pernambuco pelo apoio, bem como ao Instituto Nacional de Ciência e Tecnologia em Salinidade (INCTSal).

\section{LiTERATURA CITADA}

Albuquerque Filho, J. A. C.; Lima, V. L. A. de; Menezes, D.; Azevedo, C. A. V. de; Dantas Neto, J.; Soares Júnior, J. G. Características vegetativas do coentro submetido a doses do polímero hidro absorvente e lâminas de irrigação. Revista Brasileira de Engenharia Agrícola e Ambiental, v.13, p.671-679, 2009.

Armas, C.; Padilla, F. M.; Pugnaire, F. I.; Jackson, R. B. Hydraulic lift and tolerance to salinity of semiarid species: Consequences for species interactions. Ecologia, v.162, p.11-21, 2010.

Assis Júnior, J. O.; Lacerda, C. F.; Silva, F. B.; Silva, F. L. B.; Bezerra, M. A.; Gheyi, H. R. Produtividade do feijão-decorda e acúmulo de sais no solo em função da fração de lixiviação e da salinidade da água de irrigação. Engenharia Agrícola, v.27, p.702-713, 2007.

Baghalian, K.; Haghiry, A.; Naghavi, M. R.; Mohammadi, A. Effect of saline irrigation water on agronomical and phytochemical characters of chamomile (Matricaria recutita L.). Scientia Horticulturae, v.116, p.437-441, 2008.

Bezerra, A. K. P.; Lacerda, C. F.; Hernandez, F. F. F.; Silva, F. B.; Gheyi, H. R. Rotação cultural feijão caupi/milho utilizandose águas de salinidades diferentes. Ciência Rural, v.40, p.1075-1082, 2010.

Blanco, F. F.; Folegatti, M. V.; Gheyi, H. R.; Fernandes, P. D. Growth and yield of corn irrigated with saline water. Scientia Agrícola, v.65, p.574-580, 2008.

Cavalcanti, F. J. A. Recomendações de adubação para o Estado de Pernambuco. 3.ed. Recife: Instituto Agronômico de Pernambuco, 2008. 212p.

Duarte, S. N.; Dias, N. S.; Teles Filho, J. F. Recuperação de um solo salinizado devido a excesso de fertilizantes em ambiente protegido. Irriga, v.12, p.422-428, 2007.

FAO - Food Agricultural Organization. < http://faostat.fao.org/ faostat>. 19 Jan. 2006.

Freire, M. B. G. S.; Freire, F. J. Fertilidade do solo e seu manejo em solos afetados por sais. In: Novais, R. F.; Alvarez, V. V. H.; Barros, N. F.; Fontes, R. L. F.; Cantaritti, R. B.; Neves, J. C. L. (ed.). Fertilidade do solo: Viçosa: SBCS, 2007. p.929-954.

Garcia, G. O.; Ferreira, P. A.; Miranda, G. V.; Oliveira, F. G.; Santos, D. B. Índice fisiológico, crescimento e produção do milho irrigado com água salina. Irriga, v.12, p.307-325. 2007.
Gomes, K. R.; Amorim, A. V.; Ferreira, F. J.; Augusto Filho, F. L.; Lacerda, C. F.; Gomes Filho, E. Respostas de crescimento e fisiologia do milho submetido a estresse salino com diferentes espaçamentos de cultivo. Revista Brasileira de Engenharia Agrícola e Ambiental, v.15, p.365-370, 2011.

Holanda Filho, R. S. F.; Santos, D. B. dos; Azevedo, C. A. V. de; Coelho, E. F.; Lima, V. L. A. de. Água salina nos atributos químicos do solo e no estado nutricional da mandioqueira. Revista Brasileira de Engenharia Agrícola e Ambiental, v.15, p.60-66, 2011.

Katerji, N.; van Horn, J. W.; Hamdy, A.; Mastrorilli, M. Comparison of corn yield response to plant water stress caused by salinity and by drought. Agricultural Water Management, v.65, p.95-101, 2004.

Katerji, N.; van Horn, J. W.; Hamdy, A.; Mastrorilli, M.; Oweis,T.; Malhotra, R.S. Response to soil salinity of two chickpea varieties differing in drought tolerance. Agricultural Water Management, v.50, p.83-96, 2001.

Lacerda, C. F.; Sousa, G. G.; Silva, F. L. B.; Guimarães, F. V. A.; Silva, G. L.; Cavalcante, L. F. Soil salinization and maize and cowpea yield in the crop rotation system using saline waters. Engenharia Agrícola, v.31, p.663-675. 2011.

Leite, E. M. Utilização de corretivos químicos em solos degradados por sódio usando milheto (Pennisetum americanum L.) como planta teste. Areia: UFPB, 2005. 62p. Dissertação Mestrado

Mcwilliams, D. Rio Grande regional soil and water series: Soil salinity and sodicity limits efficient plant growth and water use. Guide A-140. Las Cruces: New Mexico State University, 2003.

Oliveira, F. G.; Ferreira, P. A.; Santos, D. B. dos; Garcia, G. O. Índice diário de estresse hídrico do feijoeiro irrigado com água salina. Revista Brasileira de Engenharia Agrícola e Ambiental, v.9, (Suplemento), p.6-10, 2005.

Pizarro, F. Riegos localizados de alta freqüência-goteomicroaspersor-exudacion. 3.ed. Madrid: Mundi-Prensa, 1996. $513 p$.

Rhoades, J. D.; Kandiah, A.; Mashali, A. M. Uso de águas salinas para produção agrícola. Tradução de Gheyi, H. R.; Sousa, J. R.; Queiroz, J. E. Campina Grande: UFPB, 1992. $117 \mathrm{p}$.

Richards, L.A. Diagnosis and improvement of saline and alkali soils. Washington: United States Salinity Laboratory, 1954. 160p. USDA. Agriculture Hand book, 60

Santos, D. B. dos; Ferreira, P. A.; Oliveira, F. G.; Garcia, G. O.; Carneiro, J. E. S.; Cano, M. A. O. Estratégias de manejo da irrigação do feijoeiro com água salina. Revista Brasileira de Engenharia Agrícola e Ambiental,v.9 (suplemento), p.16-20, 2005.

Silva, E. F.; Assis Júnior, R. M.; Sousa, J. I. G. Efeito da qualidade da água de irrigação sobre atributos hídricos de um neossolo. Revista Brasileira de Ciência do Solo, v.29, p.389396, 2005.

Silva, S. M. S.; Alves, A. N.; Gheyi, H. R.; Beltrão, N. E. de M.; Severino, L. S.; Soares, F. A. L. Desenvolvimento e produção de duas cultivares de mamoneira sob estresse salino. Revista Brasileira de Engenharia Agrícola e Ambiental. v.12, p.335342, 2008. 
Willadino, L.;Câmara, T. R.; Santos, M. A.; Torne, J. M. Obtenção de uma linhagem de milho tolerante ao stress salino mediante a cultura de anteras. Pesquisa Agropecuária Brasileira, v.30, p.1313-1318, 1994.
Wilson, C.; Liu, X.; Lesch, S. M.; Suarez, D. L. Growth response of major USA cowpea cultivars: II. Effect of salinity on leaf gas exchange. Plant Science, v.170, p.10951101, 2006. 